\title{
Effect of Granules Size on the Release Kinetics of Ibuprofen from Its Matrix Tablet
}

\author{
Ekaete I. Akpabio ${ }^{*}$, Daniel E. Effiong1, Timma 0. Uwah ${ }^{1}$, Sabinus I. Ofoefule ${ }^{2}$ \\ ${ }^{1}$ Pharmaceutics and Pharmaceutical Technology, University of Uyo, Uyo, Nigeria \\ ${ }^{2}$ Pharmaceutical Technology, University of Nigeria, Nsukka, Nigeria \\ Email: * pharmeka2000@yahoo.com
}

How to cite this paper: Akpabio, E.I., Effiong, D.E., Uwah, T.O. and Ofoefule, S.I. (2022) Effect of Granules Size on the Release Kinetics of Ibuprofen from Its Matrix Tablet. Open Access Library Journal, 9: e7920. https://doi.org/10.4236/oalib.1107920

Received: September 20, 2021

Accepted: February 21, 2022

Published: February 24, 2022

Copyright $\odot 2022$ by author(s) and Open Access Library Inc.

This work is licensed under the Creative Commons Attribution International License (CC BY 4.0).

http://creativecommons.org/licenses/by/4.0/

\begin{abstract}
Background: Sustained-release matrix tablets have been used to present a wide range of drugs for oral use. Matrix tablets are formed by compaction of drug granules prepared by granulation of drug-polymer mix. Objective: This study was to evaluate different granule sizes of ibuprofen produced using two polymers and determine whether granule size and polymer type influenced Ibuprofen release from the sustained-release matrix tablets. Method: Ethyl cellulose and Carbopol 940 were used separately at a concentration of $20 \%$ to prepare ibuprofen granules. Dried granules were sieved into sizes; 0.25, 0.5, 1 and $2 \mathrm{~mm}$ respectively. Compatibility studies were carried out using FT-IR and DSC. The micromeritics of batches of the different sizes of granules and physico-mechanical properties of tablets formed were evaluated. The dissolution profiles were assessed in-vitro using enzyme-absent phosphate buffer for 8 hours. Drug percentage release was fitted into release kinetic models so as to describe drug release pattern and mechanism. Results: Swelling index in both polymers increased with granule size. All tablets passed mechanical tests of crushing strength and friability (with ranges of $6.2-8.6 \mathrm{KgF}$ and $0.4 \%$ $0.9 \%$ respectively). For the Ethyl cellulose matrix tablet, $\mathrm{E}_{1}$ followed first order $\left(R^{2}=0.987\right)$, but $E_{2}$ and $E_{3}$ are best described by the Korsemeyer-Peppas $\left(\mathrm{R}^{2}=0.9738\right.$ and 0.9802 respectively) whereas $\mathrm{E}_{4}$ followed Zero order kinetic model $\left(R^{2}=0.9844\right)$. However, the Carbopol 940 matrix tablet, $C_{1}-C_{2}$ followed the Korsemeyer-Peppas model $\left(\mathrm{R}^{2}=0.9795\right.$ and 0.9732 respectively). Also while $C_{3}$ best fits Higuchi kinetics $\left(R^{2}=0.9853\right)$, the $C_{4}$ is best explained using the zero order (0.9711). Conclusion: Although tablets of larger sized granules irrespective of the polymer used were best described by zero order $\left(\mathrm{E}_{4}\right.$ and $\left.\mathrm{C}_{4}\right)$, the smaller sizes $\left(\mathrm{E}_{2}\right.$ and $\left.\mathrm{C}_{2}\right)$ followed Korsemeyer-Peppas model, the polymer used or granule size had no statistically significant effect on the percentage drug release of ibuprofen from tablet matrix.
\end{abstract}

\section{Subject Areas}

Drug and Device 


\section{Keywords}

Release Kinetics, Granule Size, Ibuprofen, Sustained-Release Tablet, Polymer-Drug Matrix

\section{Introduction}

Due to the associated low incidence of side effects and wide application to all age groups, Ibuprofen, one of the mostly used non-steroidal anti-inflammatory drugs (NSAIDS) has been well prescribed and presented in different dosage forms [1]. The common forms are those administered via the oral route because of its ease of application, available technology and patient acceptability. As oral solids readily found in the Nigerian pharmaceutical market, ibuprofen has been presented as hard capsule-containing powder $\left(\right.$ Vitamofen $^{\circledR}$ and Ibucap ${ }^{\circledR}$ ), immediate release tablet $\left(\operatorname{Reprofen}^{\circledR}\right)$, prolonged-release microbeads capsule (neurofen back pain ${ }^{\circledR}$ ), as a semisolid gel (neurofen softgel ${ }^{\circledR}$ ), drug-in-lipid matrix as liquid in soft capsule (emprofen ${ }^{\circledR}$ ) and as matrix caplets (Brustan- $\mathrm{N}^{\circledR}$ ) [2] [3].

The matrix tablet is a commonly found solid formulation of ibuprofen of all the oral presentations of the drug in the Nigerian pharmaceutical market. A possible reason could be due to available technology and comparatively low cost of production.

The matrix tablets are usually formed by the compaction of granules of the active ingredient. In many matrix tablet formulations, a particular prepared granule size of the drug is used and the resultant matrix is evaluated for regulatory approval. Particle size has been known and reported to influence micromeritics, dissolution, solubility, and bioavailability and enhance drug exposure. It affects other similar processes because it gives information on the specific surface area to volume ratio of the particle and its associated effects [4] [5] [6] [7]. Granule and tablet properties can be influenced by size as it affects segregation after mixing, porosity in the granule bed, even the granules flow properties [8]. Mathematical models such as the zero order, Higuchi model or the KorsmeyerPeppas model have been used to describe drug release kinetics of matrix tablets. Such matrix compacts are composed of varying sizes or predominantly a particular size of granules. Only few isolated studies, from our literature search, were found, to have investigated the effect of particle size on the release kinetics of a formulated solid dosage form, even though none was specific to ibuprofen matrix tablets [9] [10] [11]. On this, cogent questions arise such as does the size of the granules in the matrix affect the way the active ingredient (e.g., ibuprofen) is released? Is there any relationship in the polymer used on the release kinetics of the drug, ibuprofen?

These are questions that this research aims to answer by using two different polymers in formulating ibuprofen matrix tablet employing different well-defined granule sizes. It then investigates to what extent the granule size influences the 
release kinetics of ibuprofen (chemical structure shown in Figure 1). Ehtyl cellulose and Carbopol 940 are the two polymers employed in this study as the matrix formers. While ethyl cellulose is widely used in oral and topical pharmaceutical formulations, its main use in oral formulation is as a hydrophobic polymer for tablets and granules. Such polymer is used as matrix former to modify release of the drug actives, improve on stability of a drug formulation or conceal an unpleasant taste of a drug [12]. Carbopol 940 on the other hand is a synthetic high molecular weight homopolymer of acrylic acid, cross-linked with alkylether. Carbopol 940 is a useful suspending agent and thickener in suspensions and emulsions, improving viscosity of cosmetics or as matrix former in tablets. Figure 1 shows the chemical structure of ibuprofen.

\section{Materials and Methods}

\subsection{Materials}

Ibuprofen powder (Pauco Pharmaceutical Industry Nig. Ltd.), ethanol (SigmaAldrich, Germany), Ethylcellulose (Sigma-Aldrich, Germany), Carbopol 940 (Sigma-Aldrich, Germany), Magnesium stearate, talc (BDH Chemical Ltd., England), microcrystalline cellulose PH 101 (Gujarat Microwax Ltd., India).

\subsection{Compatibility Studies}

\subsubsection{Differential Scanning Calorimetry (DSC)}

Thermograms of the pure Ibuprofen and Ibuprofen-polymers were recorded with a DSC machine, (DSC 204, NETZCH TECH.LTD., Germany). A 1 mg quantity of the sample was weighed into an aluminum pan which crimped non-hermetically and in a liquid nitrogen environment at a flow rate of $7.0 \mathrm{ml} / \mathrm{min}$ to $20.0 \mathrm{~mL} / \mathrm{min}$ for maintaining inert atmospheres. The heating range was $50^{\circ} \mathrm{C}-600^{\circ} \mathrm{C}$ at a rate of $10^{\circ} \mathrm{C}$ per minute.

\subsubsection{Fourier-Transform Iinfrared Spectroscopy (FT-IR)}

The FT-IR spectra of the ibuprofen powder and ibuprofen-polymer mixtures

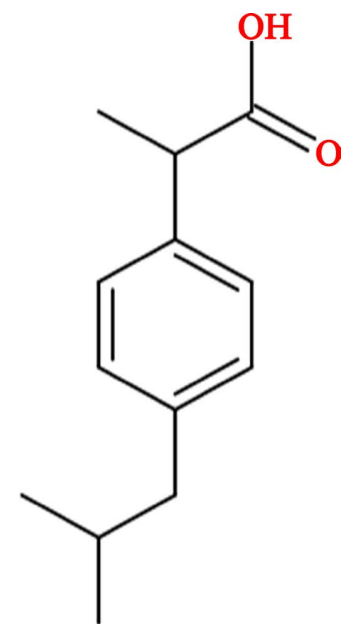

Figure 1. Chemical structure of Ibuprofen. 
Table 1. Composition of Ibuprofen tablets.

\begin{tabular}{ccccccccc}
\hline & \multicolumn{4}{c}{ Batch 1 } & \multicolumn{5}{c}{ Batch 2 } \\
\cline { 2 - 9 } Ingredients per tablet & E1 & E2 & E3 & E4 & C1 & C2 & C3 & C4 \\
\hline Ibuprofen (mg) & 200 & 200 & 200 & 200 & 200 & 200 & 200 & 200 \\
Ethylcellulose (\%) & 20 & 20 & 20 & 20 & - & - & - & - \\
Carbopol 940 (\%) & - & - & - & - & 20 & 20 & 20 & 20 \\
Talc (\%) & 1 & 1 & 1 & 1 & 1 & 1 & 1 & 1 \\
Magnesium stearate & 1 & 1 & 1 & 1 & 1 & 1 & 1 & 1 \\
$\begin{array}{c}\text { Microcrystalline cellulose } \\
\text { (MCC)qs to }\end{array}$ & $400 \mathrm{mg}$ & $400 \mathrm{mg}$ & $400 \mathrm{mg}$ & $400 \mathrm{mg}$ & $400 \mathrm{mg}$ & $400 \mathrm{mg}$ & $400 \mathrm{mg}$ & $400 \mathrm{mg}$ \\
\hline
\end{tabular}

Key: Batch 1 or the E series: Batch containing $20 \%$ of Ethyl cellulose as matrix former to produce granules. The granules were of sizes E1 $(0.25 \mathrm{~mm})$, E2 $(0.5 \mathrm{~mm}), \mathrm{E} 3(1.0 \mathrm{~mm})$, and E4 $(2.0 \mathrm{~mm})$. Batch 2, the C series is Batch with $20 \%$ of Carbopol 940 as matrix former and granules formed were of sizes C1 (0.25 $\mathrm{mm}), \mathrm{C} 2(0.5 \mathrm{~mm}), \mathrm{C} 3(1.0 \mathrm{~mm}), \mathrm{C} 4(2.0 \mathrm{~mm})$.

were recorded using FTIR-spectrometer (WQF 520, Beijing Rayleigh Analytical Instrument Corporation, BRAIC China). The pellets were prepared on the potassium bromide $(\mathrm{KBr})$-press and the spectra were recorded over the wave number range of 3900 to $600 \mathrm{~cm}^{-1}$.

\subsection{Preparation of Ibuprofen Granules}

Granules of ibuprofen were prepared by the wet granulation method. Two batches of granules were prepared using 2 different polymers (Ethylcellulose for batch 1 and Carbopol 940 for batch 2). Each polymer was used at 20\% polymer concentration. Each batch of granule was prepared by mixing $40 \mathrm{~g}$ of ibuprofen powder and $5.6 \mathrm{~g}$ of microcrystalline cellulose in a mortar with appropriate binder in specified quantity dissolved in $95 \%$ ethanol to obtain a damp cohesive mass. Granules prepared with different polymers were passed through a $4 \mathrm{~mm}$ stainless sieve using a spatula, then dried in the laboratory oven (Techmel Techmel, USA) at $60^{\circ} \mathrm{C}$ for 1 hour. The dried granules were placed in a sieve shaker (Endecott, UK) comprising a stack of sieve ranging from $2 \mathrm{~mm}-0.25 \mathrm{~mm}$ respectively to obtain finer granules. Four different particle sizes were obtained from each batch.

\subsection{Compaction of Granules}

Each mass of granules with specific size were lubricated with $1 \%$ each of talc and aerosil, then compressed into solid compacts using a single punch tableting press (Cadmach, India) fitted with $12.5 \mathrm{~mm}$ flat faced punches at a constant compression force of $15 \mathrm{KN}$.

\subsection{Evaluation of Granules}

The micromeritics and densities of the granules were evaluated as described in literature [13]. 


\subsection{Evaluation of Matrix Tablet}

\subsubsection{Tablet Dimensions and Mechanical Properties}

The breaking force of 10 tablets selected from each batch was determined using the Monsanto hardness tester (Rolex, Chandigarh) while the friability of 5 selected tablets were determined using a Roche friabilator (UNID 056830 Campbell Electronic, Mumbai, India).

The tablet dimensions (thickness and diameter) were measured using the micrometer screw gauge (KFW Scientific Industries Ambala Cantt, India). Ten (10) tablets randomly selected from each batch were measured and the mean values determined.

\subsubsection{Swelling Index}

One tablet from each batch was weighed and kept in a petri dish containing $\mathrm{NaOH}$ buffer 7.2 for four hours, after which the tablet was withdrawn and then the tablet was re-weighed. The percentage weight gained by the tablet was calculated as follows:

$$
\text { Swelling index }=\frac{M_{t}-M_{o}}{M_{0}} \times 100
$$

$M_{t}=$ weight of tablet at a time $(t)$;

$M_{o}=$ weight of tablet at time $\left(t_{o}\right)$.

\subsection{Dissolution Study}

The release profile of ibuprofen matrix tablet was studied using $900 \mathrm{ml}$ of phosphate buffer ( $\mathrm{pH}$ 6.8) dissolution medium employing the United State Pharmacopoeia (USP) dissolution testing apparatus 1 (basket method). The medium was maintained at $37^{\circ} \mathrm{C} \pm 0.5^{\circ} \mathrm{C}$ and $50 \mathrm{rpm} .10 \mathrm{ml}$ aliquot was withdrawn and immediately replaced with equal volume of fresh dissolution medium at $30 \mathrm{mi}$ nutes intervals, for 8 hours, then filtered through a Whatmann filter paper No. 2 . The drug concentration at each time interval was determined from the filtrate which was assayed using the UV 2100 spectrophotometer at wavelength of 263 $\mathrm{nm}$, where ibuprofen exhibits peak absorbance.

\subsection{Standard Calibration Curve}

A $500 \mathrm{mg}$ of ibuprofen powder was dissolved in $50 \mathrm{ml}$ of phosphate buffer ( $\mathrm{pH}$ 6.8 ) in a $100 \mathrm{ml}$ beaker to produce an ibuprofen concentration of $1 \mathrm{mg} / \mathrm{ml}$. A serial dilution was made from the stock solution to give concentrations of $1,2,3$, 4, 5, 6 and $7 \mu \mathrm{g} / \mathrm{ml}$ respectively. Absorbance of the resultant serial dilutions was read at wavelength $263 \mathrm{~nm}$ using a UV spectrophotometer. Graphical plot, using the values of concentration and absorbance, was done using Microsoft excel to obtain the standard curve.

\subsection{Kinetic Analysis of In-Vitro Release Rate}

The results of in-vitro release profile obtained for all the formulations were fitted 
into five release kinetic equation models: zero order kinetic model (cumulative \% drug release versus time), first order kinetic model (log cumulative percentage drug remaining versus time), Higuchi's model (cumulative \% drug released versus square root of time), Korsemeyer-Peppa's model (log cumulative \% drug released versus log time) and the Hixson Crowel's model (cube root of drug release vs. time). The release pattern is then described by the models to which the data best fits.

\section{Results and Discussion}

\subsection{Compatibility and Thermal Stability Studies of Ibuprofen/Excipients}

The DSC thermograms for pure ibuprofen and polymers are shown in Figures 2-4. The melting point of the pure drug molecule (ibuprofen) as obtained from the endothermic peak isotherm was at $79.7^{\circ} \mathrm{C}$. This is in agreement with report in literature [14]. The endothermic peak observed for Ibuprofen and ethylcellulose was at $77.8^{\circ} \mathrm{C}$. This was no major change in the peak from that obtained for pure Ibuprofen. This implies that there was no interaction between pure Ibuprofen and ethylcellulose. However, the transition energy for denaturation of the mixture is $3.555 \mathrm{~J} / \mathrm{g} / \mathrm{K}$. Comparing that to the transition energy required to breakdown pure ibuprofen, it was reduced to half of its original value, implying that ethyl cellulose may lower the thermal stability of ibuprofen and thus be reconsidered when decided to be used to serve as an ideal excipient for the preparation of ibuprofen products.

The endothermic peak obtained for the Ibuprofen and Carbopol 940 mixture

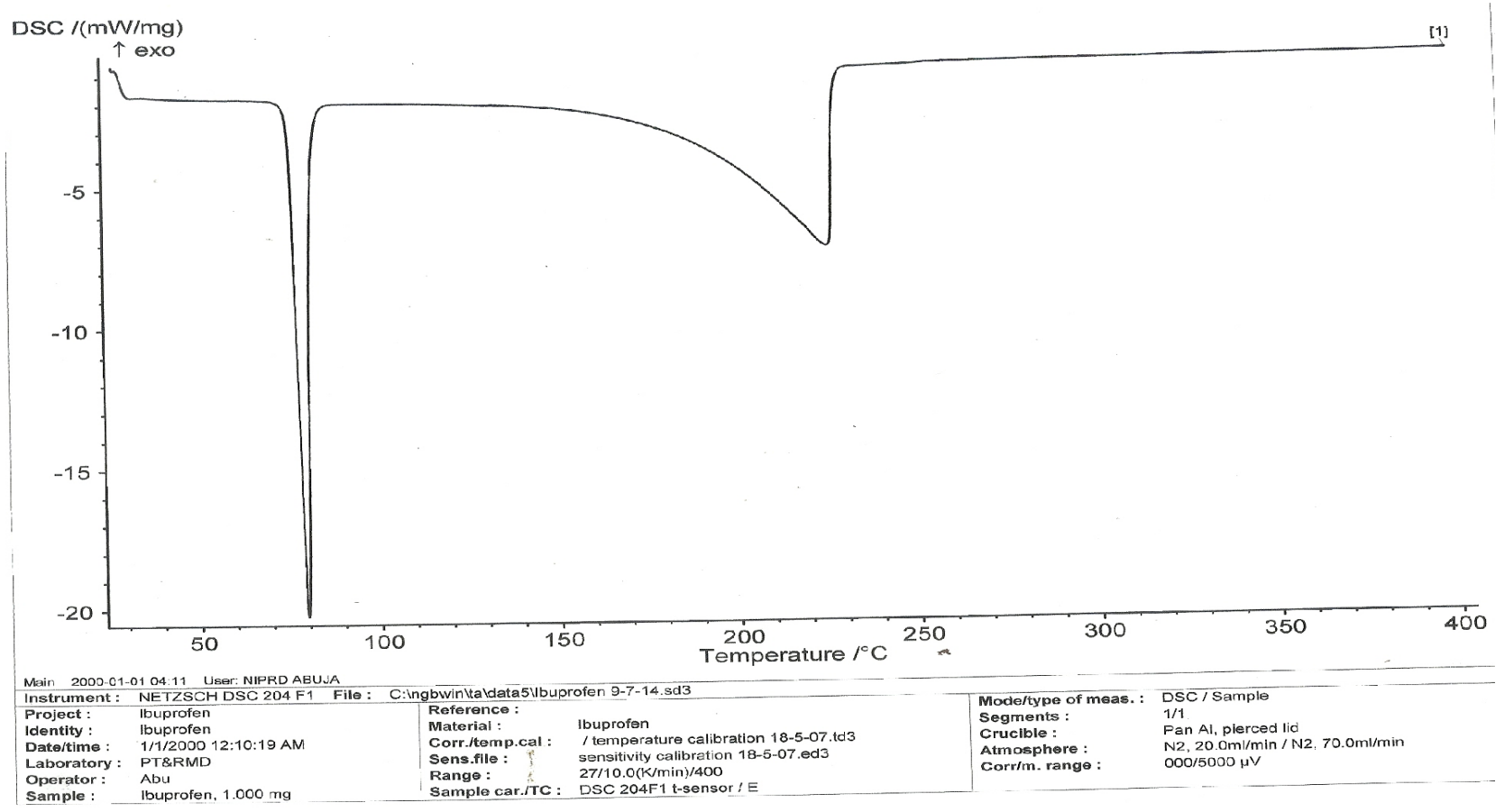

Figure 2. DSC Thermogram of pure ibuprofen powder. 


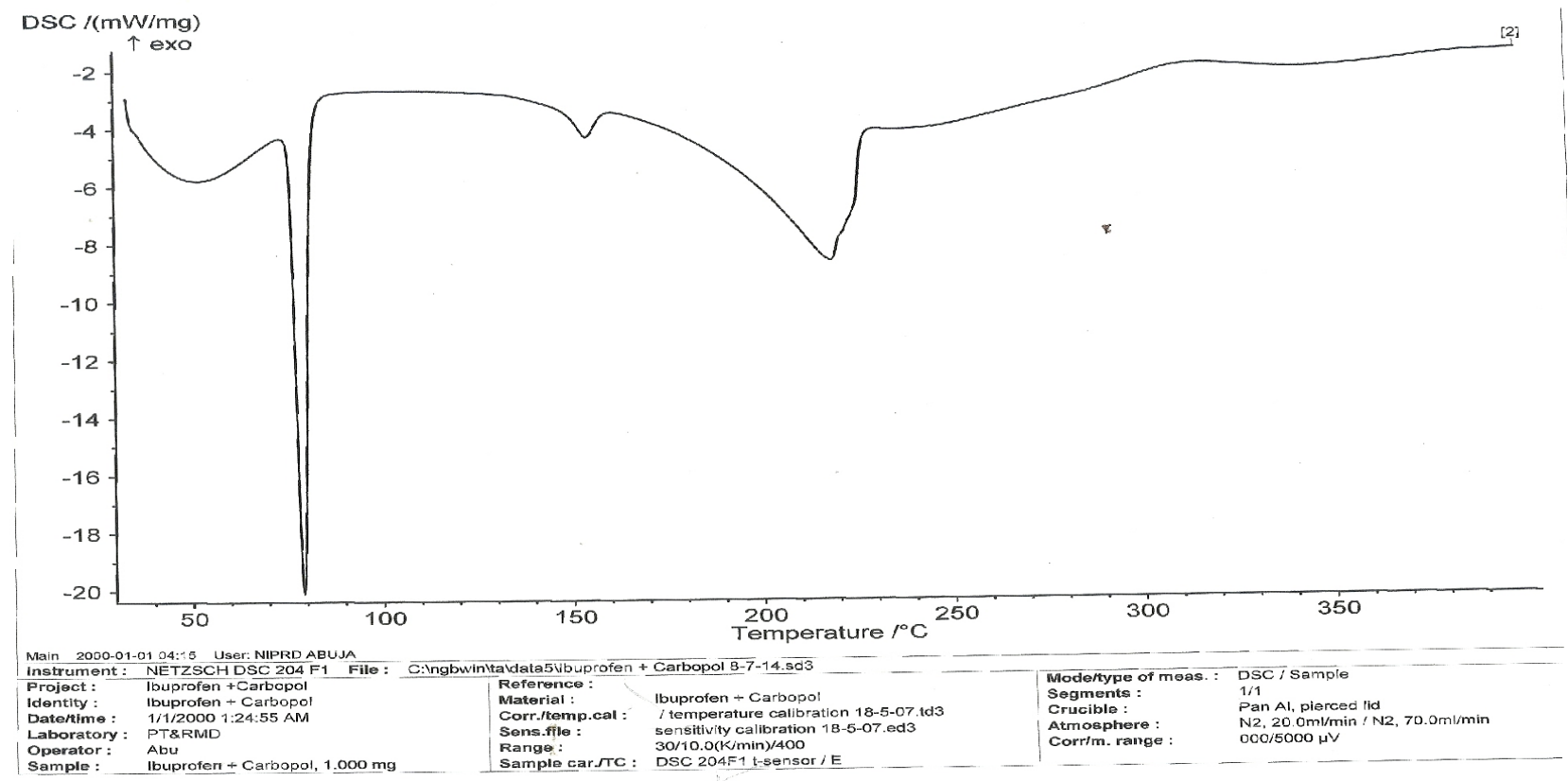

Figure 3. DSC thermogram of ibuprofen and physical mixture of Carbopol 940.

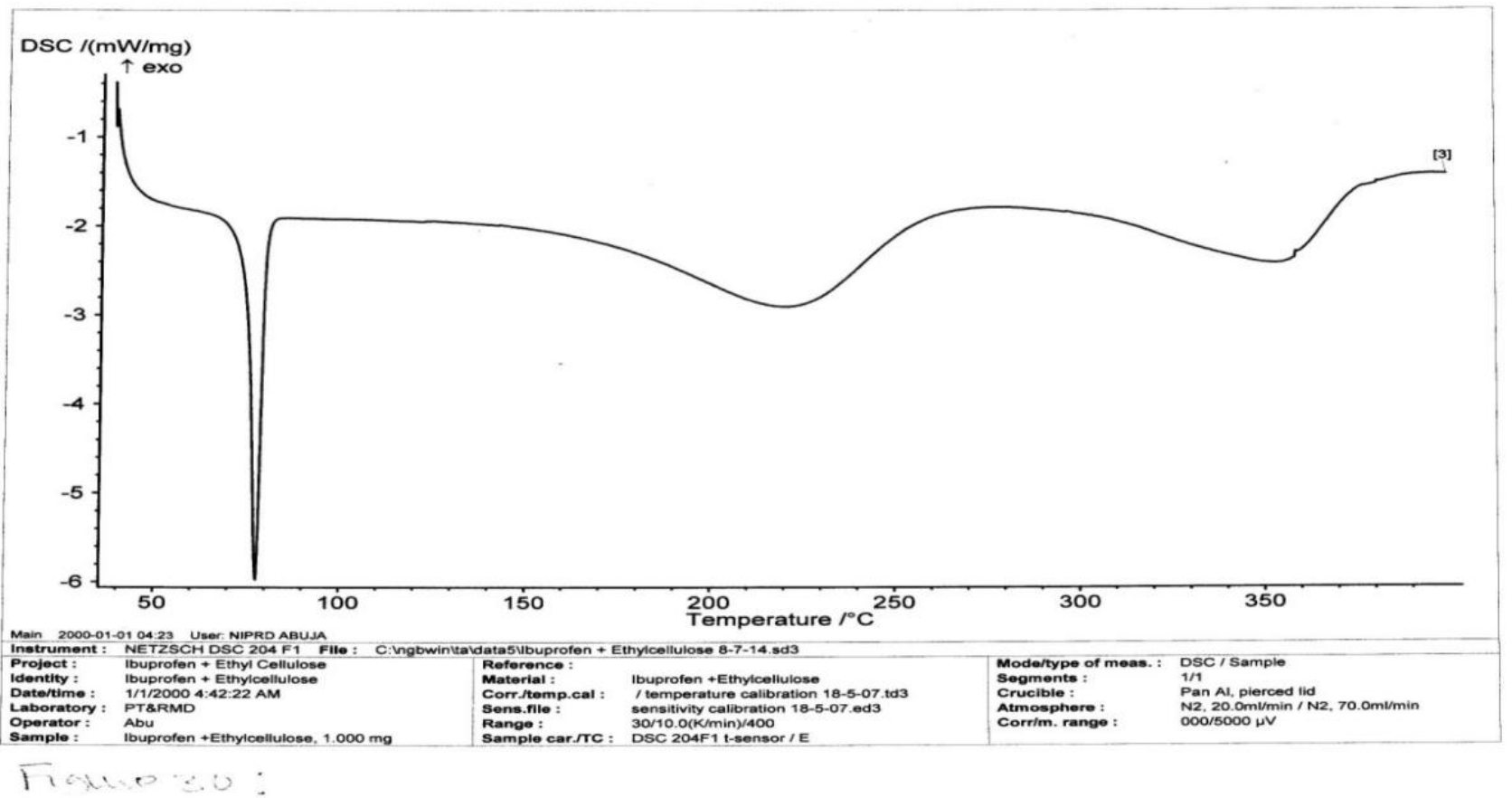

Figure 4. DSC thermogram of the physical mixture of Ibuprofen and ethyl cellulose.

was $79.1^{\circ} \mathrm{C}$. This is not an appreciable difference when compared with peak of pure Ibuprofen [15]. The transition energy required to denature Ibuprofen-Carbopol 940 mixture was $6.805 \mathrm{~J} / \mathrm{g} / \mathrm{K}$. This energy is slightly higher than that required to break down the pure drug. Such slight increase in the transition energy could confer some stability on ibuprofen and hence, Carbopol 940 can be used as a compatible excipient for the production of ibuprofen tablets [16]. 
Ibuprofen and the polymers were also evaluated using the FT-IR peak matching method. The results are shown in Figures 5-7. Pure lbuprofen showed several peaks at the finger print region. The physical mixture of ibuprofen and ethylcellulose exhibited similar peaks at the finger print region. These observed peaks indicate that the pure drug did not change in the physical mixture with ethylcellulose, hence no adverse interaction occurred between the ethylcellulose and lbuprofen [15]. The observed peaks of the physical mixture of Ibuprofen and Carbopol 940 showed alterations when compared to that of the pure drug. This indicates a likely interaction between lbuprofen and Carbopol 940 physical

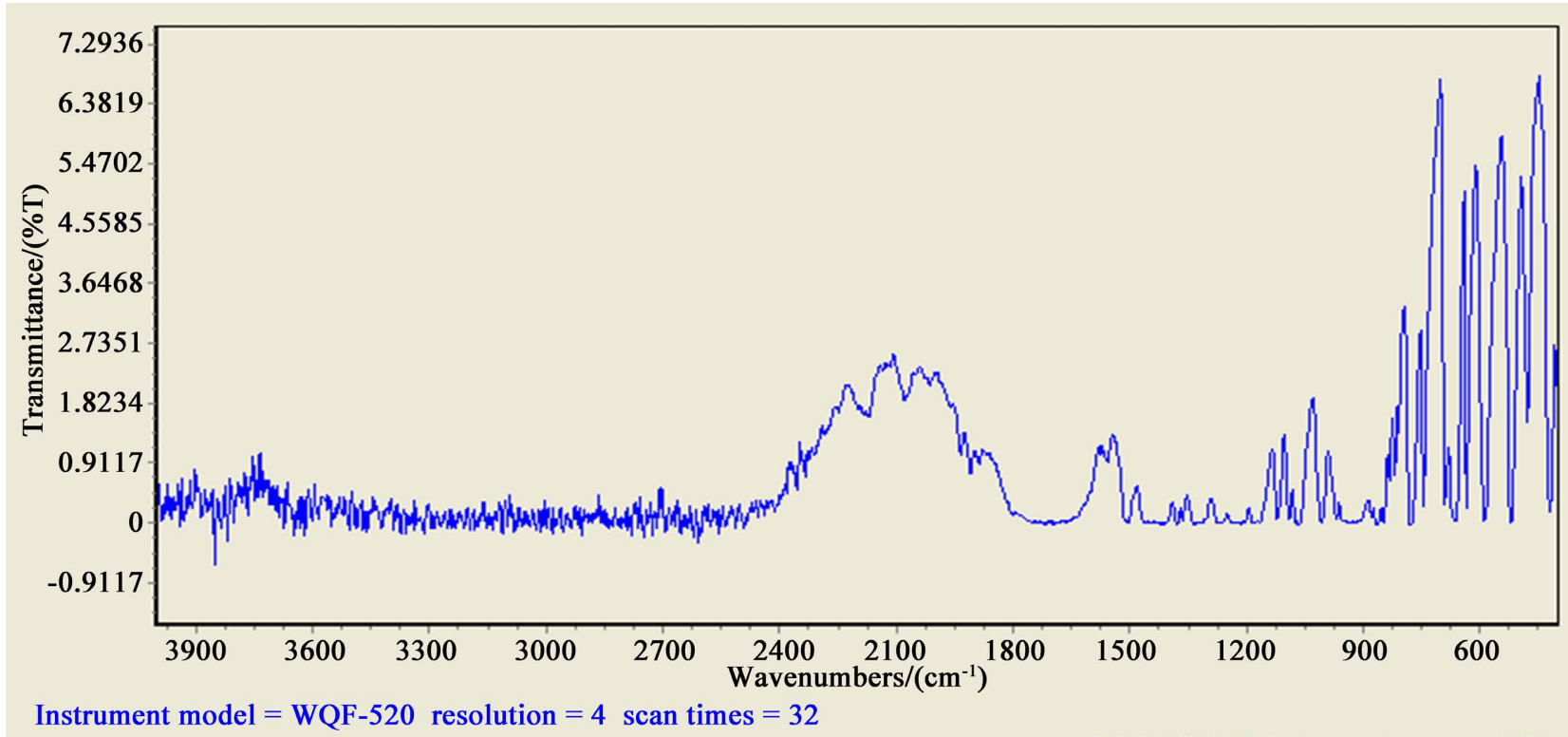

2014/5/26 17:9 Ibuprofen pure.ASF

Figure 5. FTIR spectrum of pure Ibuprofen.

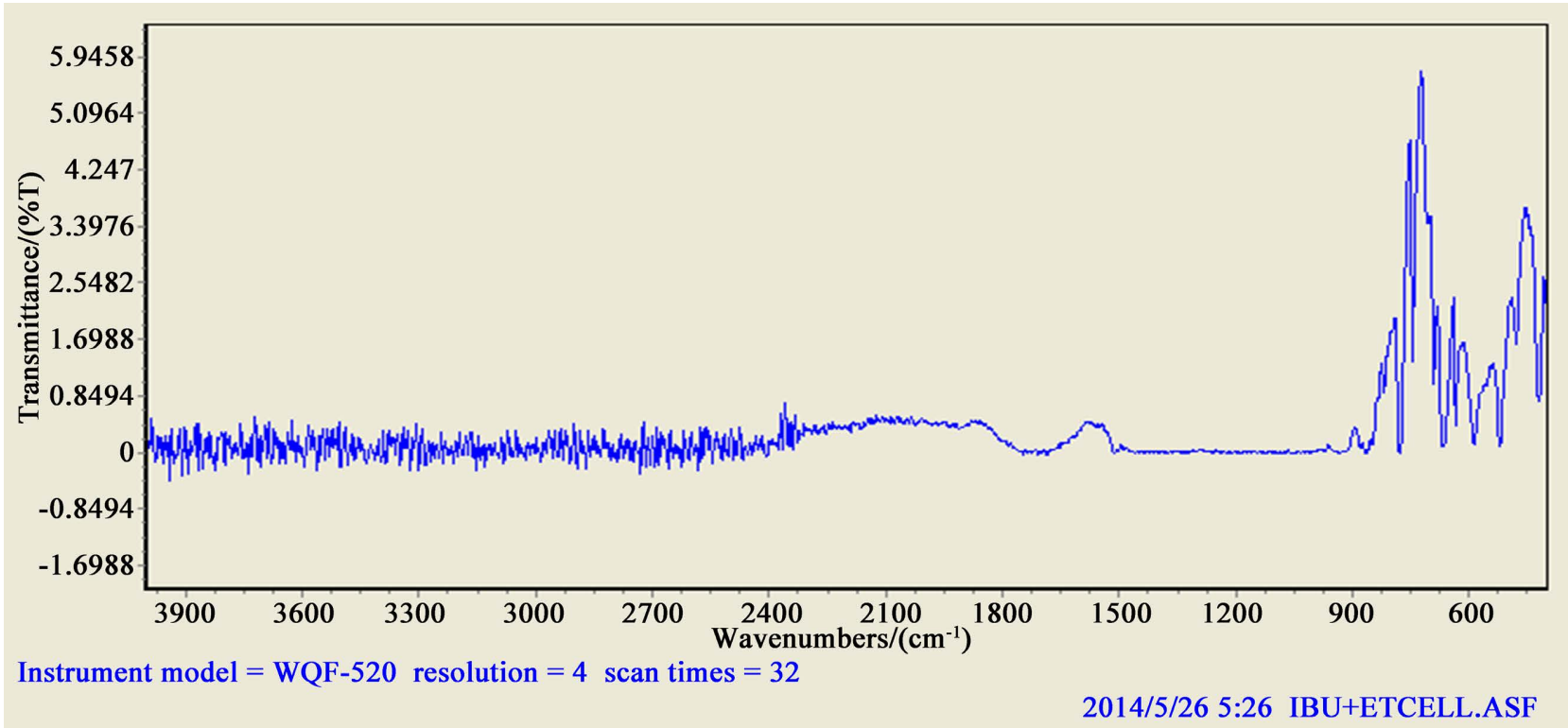

Figure 6. FTIR spectrum of the physical mixture Ibuprofen and Ethyl cellulose. 


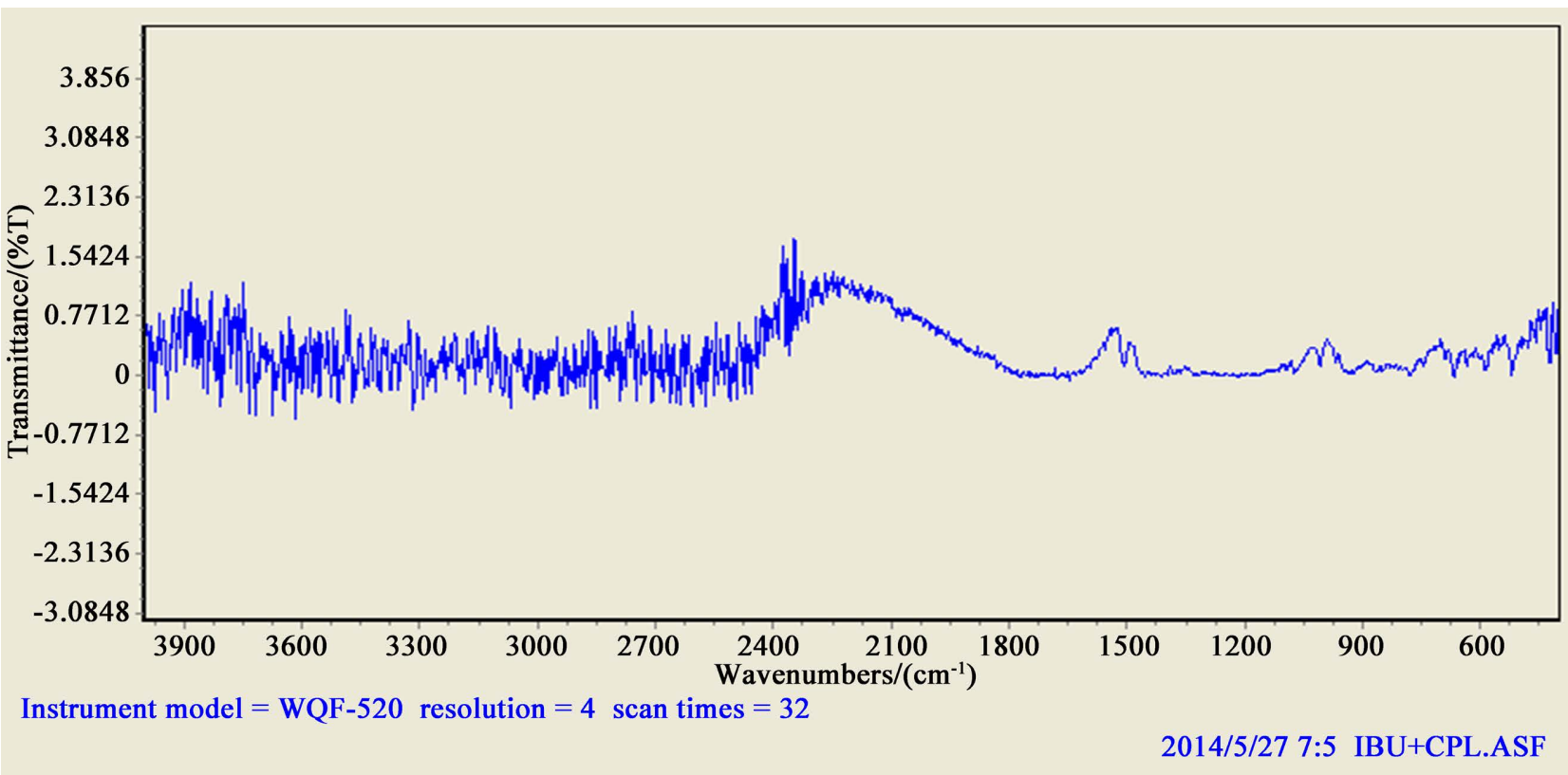

Figure 7. FTIR spectrum of the physical mixture of Ibuprofen and Carbopol 940.

mixtures. However this is not likely to affect the stability of the drug appreciably because the DSC indicates adequate compatibility between ibuprofen and the polymer.

\subsection{Physicochemical Properties of Ibuprofen Tablet}

The formulated matrix tablets exhibited satisfactory mechanical properties (Table 2). The tablet hardness ranged from 6.2 and $8.6 \mathrm{KgF}$ and they all passed the friability test, where none was cracked or cleaved but maximum weight loss after test was less than $1 \%$, the accepted official standards [17]. The tablet porosity, an indication of how well a dissolution medium will gain entry into the tablet, was within the range of $30 \%$ and $41 \%$ where size $0.50 \mathrm{~mm}$ (E2 and C2) in each respective batches showed highest values.

The extent of swelling was determined in terms of percentage weight gain by the tablet (Table 2). Swelling describes the degree of hydration of the tablet. From the study, the swelling index ranged from $19.05 \%$ to $36.58 \%$ in Batch 1 and $26.83 \%$ to $43.90 \%$ in Batch 2. Generally, swelling of the tablets batches in the study is directly related to the granules sizes. This may be as a result in larger polymer matrix is present in the granules of larger sizes. However, the degree of swelling in the two batch series, when compared showed that polymer used in batch 2 contributed to higher swelling. This disparity in swelling value can be explained due to the molecular structure of the polymers used. While ethyl cellulose (used for batch 1) are cellulose derivatives prepared by etherification of available hydroxyl groups, giving it the hydrophobic nature that likely retarded rate of solvent entry into the tablet matrix to cause higher swelling. Carbopol 940 on the other hand is a synthetic high molecular weight polymer of acrylic acid forms hydrogel in water/ alkaline medium as the carboxyl groups in its structure 
are hydrated [18]. Carbopol 940 can absorb hydrophilic solvent e.g. water readily, swelling to several of its original volume.

\subsection{In Vitro Release Studies}

In this study, in Batch 1, tablets exhibited a total percentage release of $99.04 \%$ at 8 hours while Batch 2 exhibited a maximum percentage release of $95.58 \%$ at same duration (Figure 8 and Figure 9). Batch 2 gave a lower release of the Ibuprofen from the tablets at the time under consideration. Drug release from a matrix is influenced by dissolution of the active in the device but also by polymer matrix swelling, its viscosity of on swelling, polymer erosion, and diffusion of drug out of the swollen matrix former [19]. A proper understanding of the

Table 2. Physical properties of the ibuprofen granules.

\begin{tabular}{|c|c|c|c|c|c|c|c|c|}
\hline \multirow{2}{*}{ Parameters } & \multicolumn{3}{|c|}{ Batch 1} & \multicolumn{5}{|c|}{ Batch 2} \\
\hline & $\mathrm{E} 1$ & E2 & E3 & $\mathrm{E} 4$ & $\mathrm{C} 1$ & $\mathrm{C} 2$ & $\mathrm{C} 3$ & $\mathrm{C} 4$ \\
\hline weight variation (g) & $0.41 \pm 0.02$ & $0.40 \pm 0.02$ & $0.42 \pm 0.01$ & $0.41 \pm 0.02$ & $0.42 \pm 0.02$ & $0.40 \pm 0.01$ & $0.40 \pm 0.01$ & $0.40 \pm 0.01$ \\
\hline Thickness (mm) & $3.43 \pm 0.06$ & $3.45 \pm 0.02$ & $3.39 \pm 0.01$ & $3.40 \pm 0.02$ & $3.25 \pm 0.05$ & $3.60 \pm 0.02$ & $3.67 \pm 0.06$ & $3.76 \pm 0.02$ \\
\hline Hardness (kgF) & $8.60 \pm 0.01$ & $7.60 \pm 0.46$ & $7.00 \pm 0.75$ & $6.80 \pm 0.49$ & $7.60 \pm 0.49$ & $6.80 \pm 1.09$ & $6.60 \pm 1.20$ & $6.20 \pm 1.71$ \\
\hline Diameter (mm) & $12.20 \pm 0.01$ & $12.18 \pm 0.01$ & $12.15 \pm 0.02$ & $12.13 \pm 0.01$ & $12.30 \pm 0.01$ & $12.50 \pm 0.02$ & $12.18 \pm 0.01$ & $12.15 \pm 0.02$ \\
\hline Friability (\%) & 0.91 & 0.46 & 0.45 & 0.43 & 0.96 & 0.83 & 0.76 & 0.48 \\
\hline Tablet porosity (\%) & 34.88 & 36.23 & 31.09 & 32.70 & 30.31 & 41.60 & 39.28 & 40.42 \\
\hline Swelling index (\%) & 19.05 & 26.83 & 29.27 & 36.58 & 26.83 & 29.27 & 33.33 & 43.90 \\
\hline
\end{tabular}

Key: values are presented as mean \pm S.D.

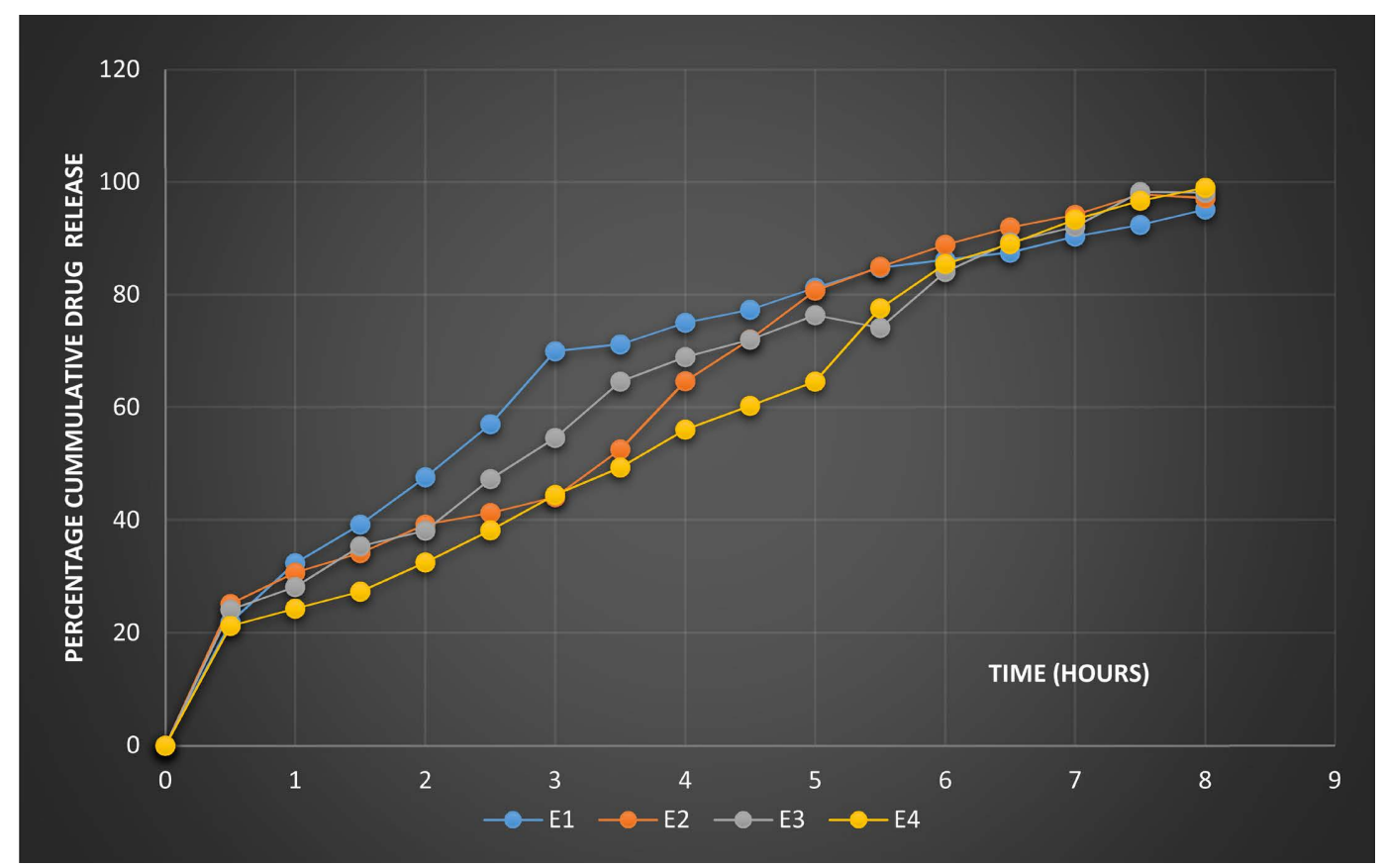

Figure 8. Ibuprofen release profile for tablet batches from ethyl cellulose matrices. 


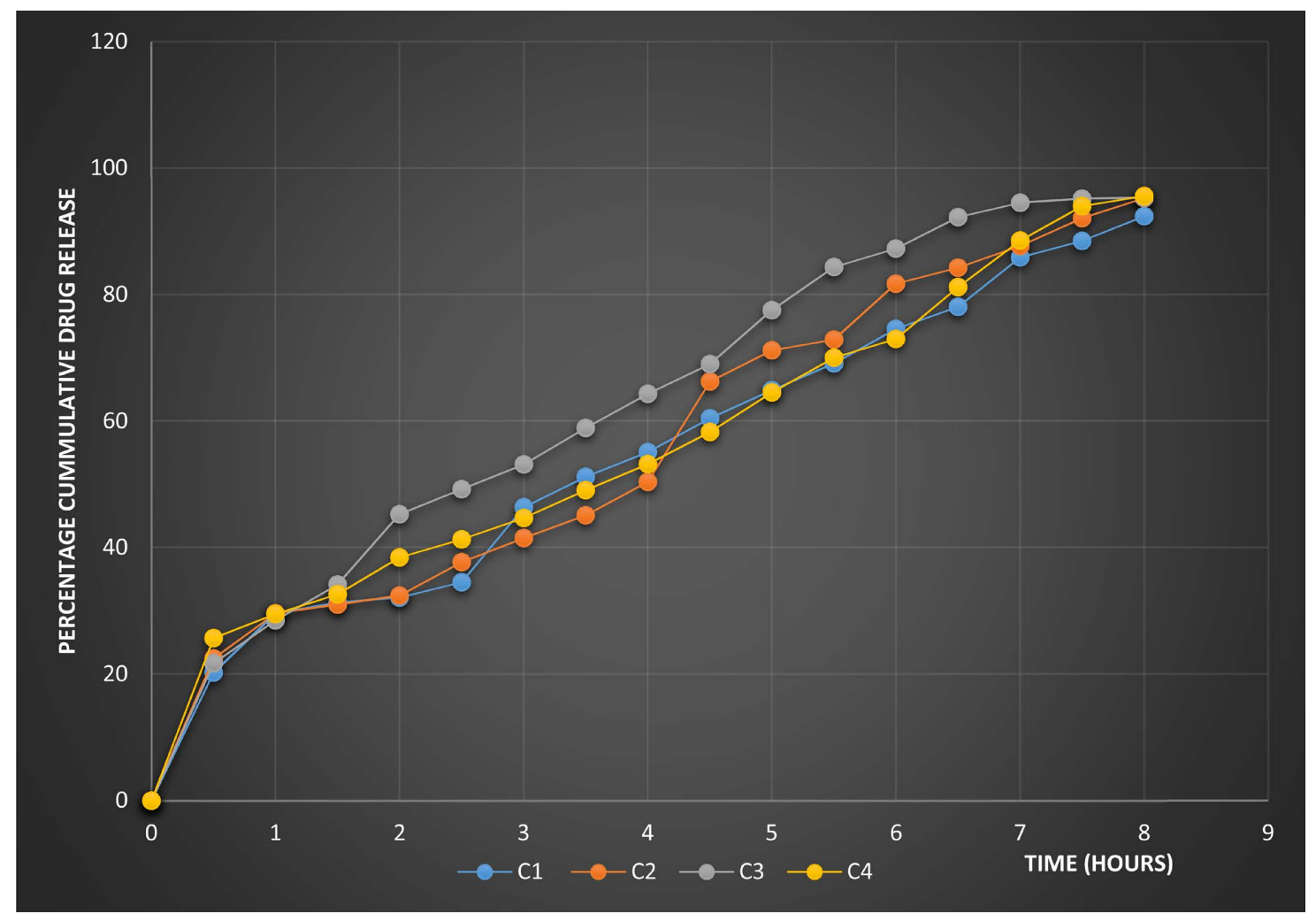

Figure 9. Release profile of Ibuprofen from tablet batches from Carbopol 940 matrix.

interplay of these factors will reflect in the explanation given for any release kinetics of a controlled release delivery system [20]. Carbopol 940 used as the matrix former for batch 2, despite higher swelling, possess greater viscosity and likely reduced drug diffusion out of the matrix. A highly viscous matrix (obtained with increase in Carbopol 940 concentration) will limit rate of drug diffusion out of the delivery device. Similar result was reported in published work where in Carbopol 940 polymer used at $36 \%$ as matrix former controlled release beyond 12 hours [18] [19] and [21].

The regression coefficients obtained for the different release kinetic models (e.g. zero order, first order and Hixson Crowel etc.) are found on Table 3.

The tablet batches most fitted to the kinetic models are reflected by the highest value of the regression coefficient in a set of models. Both E4 and C4 were best described by the zero order kinetics, meaning that a constant amount of the active is released independent of the amount of the drug in the matrix. E1 and C3 were best described by the first order and Higuchi kinetic models respectively. The tablets from the other granule sizes (E2, E3, C1 and C2) are best described by the Korsemeyer-Peppas release mechanism. The $\mathrm{n}$ values for all the tablet batches, which reflect the mechanism of release, fall within the $0.45<\mathrm{n}<$ 0.89 (n-values 0.689 to 0.719 ). This range implies that the drug release mechanism is erosion and diffusion controlled. All the formulation showed good linearity $\left(R^{2}=0.96-0.98\right)$. It can be concluded that effect of release kinetics was found to be diffusion coupled with erosion. 
Table 3. Release kinetics of ibuprofen tablet matrix.

\begin{tabular}{ccccccc}
\hline & \multicolumn{7}{c}{$\mathrm{R}^{2}$} \\
\cline { 6 - 7 } Katch/ & \multicolumn{7}{c}{ Kinetic model } & Zero order & First order & Higuchi & $\begin{array}{c}\text { Hixson- } \\
\text { Crowel }\end{array}$ & Keppas & $\mathrm{n}$ \\
\hline E1 & 0.8797 & 0.987 & 0.9809 & 0.9813 & 0.9752 & 0.719 \\
E2 & 0.9584 & 0.9111 & 0.9563 & 0.967 & 0.9738 & 0.715 \\
E3 & 0.9561 & 0.8508 & 0.9561 & 0.9551 & 0.9802 & 0.717 \\
E4 & 0.9844 & 0.9111 & 0.9426 & 0.967 & 0.9831 & 0.719 \\
C1 & 0.976 & 0.9214 & 0.9641 & 0.967 & 0.9795 & 0.698 \\
C2 & 0.9706 & 0.9041 & 0.7839 & 0.9559 & 0.9732 & 0.703 \\
C3 & 0.9559 & 0.948 & 0.9853 & 0.9827 & 0.9673 & 0.691 \\
C4 & 0.9711 & 0.844 & 0.9515 & 0.92234 & 0.9673 & 0.689 \\
\hline
\end{tabular}

Table 4. Some release kinetic parameters of ibuprofen from matrix tablet.

\begin{tabular}{ccccccccc}
\hline Time (hr)/Batches & $\mathrm{E}_{1}$ & $\mathrm{E}_{2}$ & $\mathrm{E}_{3}$ & $\mathrm{E}_{4}$ & $\mathrm{C}_{1}$ & $\mathrm{C}_{2}$ & $\mathrm{C}_{3}$ & $\mathrm{C}_{4}$ \\
\hline $\mathrm{t}_{50}$ & 2.1 & 3.3 & 2.7 & 3.5 & 3.4 & 4.0 & 2.5 & 3.6 \\
$\mathrm{t}_{90}$ & 7.0 & 6.2 & 6.7 & 6.7 & 7.7 & 7.2 & 6.3 & 7.1 \\
\hline
\end{tabular}

The time taken for $50 \%$ and $90 \%$ respectively $\left(t_{50}\right.$ and $\left.t_{90}\right)$ of the drug to be released is given in Table 4. Generally, the time for the E-series tablets to release $50 \%$ (mean time of $2.9 \mathrm{hrs}$ ) of drug is shorter than how long it took to release the remaining $40 \%$ to arrive at $90 \%$ release (mean time is $3.8 \mathrm{hrs}$ ). A possible explanation is that of gradual clogging of the pathway of dissolved drug diffusion through the capillary network within the ethyl cellulose matrix (since it is hydrophobic).

The resulting pore network becomes more tortuous resulting with slower drug release. Similar observation has been observed in published works [22]. Of the E-batch series, E1 and E3 but of the C-series C3 had the shortest time to release $50 \%$ of the drug but C1, E4 and C4 took the longest period to arrive at same $50 \%$ drug release. Both $\mathrm{E} 1$ and $\mathrm{C} 1$ had the longest time to reach $90 \%$ drug release for each of the respective batch series. A possible understanding could be that while it took longer for the tablets of larger granules to be completely wetted for the drug to become dissolved in the matrix (as seen by higher value of $t_{50}$ ), once dissolved, larger quantity of the drug is released as compared to the sum of the smaller quantities of that released from the tablets of small-sized granules.

\subsection{Effect of Polymer Type on the Release of Ibuprofen Sustained Release Tablets}

Ibuprofen is a poorly water soluble drug and its dissolution would have been a rate-limiting step towards its release. However it is soluble in the phosphate buffer used as the dissolution medium. Thus the property of polymer-type used as matrix former primarily affected rate of dissolution medium entry to drug ma- 
trix and its subsequent release after dissolution within the matrix. Since Carbopol 940, being a cross linked acrylic acid hydrophilic polymer, is swellable, can form gels of high viscosity. The tablet matrix with carbopol 940 showed rapid gel formation in the dissolution medium likely due to ionization of the carboxylic acid functional groups during neutralization in the phosphate buffer, an alkaline medium [23]. This rapid gelation led to relative retarded release of the drug. This could be due to the fact that the polymer so cross-linked inhibits the drug from penetrating the gel at high amounts. Therefore, the drug molecules would remain in the interstitial spaces within the gel domain and only initial release is relatively rapid.

Ethyl cellulose is a cellulose polymer and has shown to be efficient to control the release of ibuprofen. Ethyl cellulose is hydrophobic in nature, due to the hydrophobic barrier there is reduced wettability and reduced particle surface area available for dissolution. Ethyl cellulose releases the drug primarily through erosion. Generally, Batch 2 tablet series sustained the drug release better than batch 1 tablet series. Thus, although the type of polymer used affected the release rate at different times, there was no statistically significant difference in the polymer type used $(\mathrm{p}<0.05)$.

\subsection{Effect of Particle Size on the Release of Ibuprofen Sustained Release Tablets}

From the study carried out, increase in particle size resulted in the overall drug from the matrix tablet. Tablets with higher granule size have higher void spaces and lesser surface area to volume ratio, hence it is more porous (see Table 3 ), and the medium can easily penetrate into the tablet causing a rapid release of the drug than that of tablets with smaller particle size which have a lower void spaces.

In Batch 1, tablets from granule size of $2 \mathrm{~mm}$ released more (99.04\%) than those of $1 \mathrm{~mm}$ (98.10\%), $0.5 \mathrm{~mm}$ (97.20\%) and $0.25 \mathrm{~mm}$ (95.16\%). Also, in Batch 2, particle size of $2 \mathrm{~mm}$ released more (95.58\%) than those of $1 \mathrm{~mm}$ (95.33\%), $0.5 \mathrm{~mm}(95.29 \%)$ and $92.40 \%)$. From the result, however, there is no statistical significant difference in the effect of particle size on the release of ibuprofen sustained release tablets $(\mathrm{P}<0.05)$.

\section{Conclusion}

While the individual particle sizes seem to have an effect on the drug release kinetics of ibuprofen from the matrix system used in this study, such effects are not statistically significant. It therefore holds true that there will be no need to separate the particle sizes to respective ranges before use in formulation of matrix tablet for sustained release but a good blend of the several sizes would likely give an acceptable drug release kinetics that is within standards.

\section{Acknowledgements}

The authors acknowledge the support of the laboratory staff members and the 
Chief Technologist of the department of Pharmaceutics, University of Uyo, Nigeria for their support while the research work lasted.

\section{Source of Funding}

Authors provided funds for the work.

\section{Authors' Contribution}

E I Akpabio \& S I Ofoefule-Research concept and design;

E I Akpabio-Collection and/or assembly of data;

E I Akpabio, D E Effiong \& T O Uwah-Data analysis and interpretation;

E I Akpabio, D E Effiong \& T O Uwah-Writing the article;

E I Akpabio, D E Effiong \& T O Uwah-Critical revision of the article;

E I Akpabio \& S I Ofoefule-Final approval of article.

\section{Conflicts of Interest}

The authors declare no conflicts of interest.

\section{References}

[1] Chisholm-Burns, M.A., Schwinghammer, T.L., Malone, P.M., Kolesar, J.M., Bookstaver, P.B. and Lee, K.C. (2019) Pharmacotherapy Principles and Practice. 5th Edition, McGraw Hill, New York, 528-529.

[2] Ibuprofen Entry in Online Emdex Nigeria. https://emdex.org

[3] Neurofen. https://www.nurofen.co.uk/pages/back-pain

[4] Savjani, K.T., Gajjar, A.K. and Savjani, J.K. (2017) Drug Solubility: Importance and Enhancement Techniques. International Scholarly Research Notices, 2012, Article ID: 195727. https://doi.org/10.5402/2012/195727

[5] Kaparissides, C., Alexandridou, S., Kotti, K. and Chaitidou, S. (2006) Recent Advances in Novel Drug Delivery Systems. Journal of Nanotechnology Online, 2, 1-11.

[6] Merisko-liversidge, E.M. and Liversidge, G.G. (2008) Drug Nanoparticles: Formulating Poorly Water-Soluble Compounds. Toxicologic Pathology, 36, 43-48. https://doi.org/10.1177/0192623307310946

[7] Muller, R.H., Jacobs, C. and Kayser, O. (2001) Nanosuspensions as Particulate Drug Formulations in Therapy: Rationale for Development and What We Can Expect in the Future. Advanced Drug Delivery Reviews, 47, 3-19. https://doi.org/10.1016/S0169-409X(00)00118-6

[8] Aulton, M.E. and Taylor, K. (2018) Aulton's Pharmaceutics: The Design and Manufacture of Medicines. 5th Edition, Churchill Livingstone, London, 189-198.

[9] Sasikumar, S. (2013) Effect of Particle Size of Calcium Phosphate Based Bioceramic Drug Delivery Carrier on the Release Kinetics of Ciprofloxacin Hydrochloride: An In-Vitro Study. Frontiers of Materials Science, 7, 261-268. https://doi.org/10.1007/s11706-013-0216-6

[10] Chen, W., Palazzo, A., Hennink, W.E. and Kok, R.J. (2016) The Effect of Particle Size on Drug Loading and Release Kinetics of Gefitinib-Loaded PLGA Microspheres. Molecular Pharmaceutics, 14, 459-467. https://doi.org/10.1021/acs.molpharmaceut.6b00896 
[11] Ghosh, D., Dastidar, G.D., Bairagi, R., Abat, S. and Chatterjee, A. (2018) Effect of Particle Size on Dissolution Profile of Ciprofloxacin Hydrochloride from Floating Matrix Tablet. International Journal of Pharmaceutical Research, 10, 110-117.

[12] Shaikh, N.A., Abidi, S.E. and Block, L.H. (1987) Evaluation of Ethylcellulose as a Matrix for Prolonged Release Formulations. Part 1. Water-Soluble Drugs Acetaminophen Theophylline. Drug Development and Industrial Pharmacy, 13, 1345-1369. https://doi.org/10.3109/03639048709068380

[13] Akpabio, E.I., Effiong, D.E., Uwah, T.O. and Sunday, N.I. (2019) Formulation and In-Vitro Evaluation of Theophylline Hydrochloride Effervescent Floating Tablets: Effect of Polymer Concentration on Tablet Buoyancy. International Journal of Pharmacy and Pharmaceutical Sciences, 12, 59-65. https://doi.org/10.22159/ijpps.2020v12i1.35055

[14] Shanmugam, S., Vetrichelvan, T. and Niranjan, P. (2011) Formulation and In-Vitro Evaluation of Sustained Release Matrix Tablets of Ibuprofen. Research Journal of Pharmaceutical, Biological and Chemical Sciences, 5, 2118-2127.

[15] Ibuprofen: Open Chemistry Database. https://pubchem.ncbi.nlm.nih.gov/\#query=ibuprofen

[16] Dubernet, C., Rowland, J.C. and Benoot, J.P. (1991) Ibuprofen Loaded Ethyl Cellulose Microspheres: Analysis of the Matrix Structure by Thermal Analysis. Journal of Pharmaceutical Sciences, 80, 1029-1033. https://doi.org/10.1002/jps.2600801106

[17] Tablet Friability Entry. https://www.usp.org/sites/default/files/usp/document/harmonization/gen-chapter/g 06_pf_ira_32_2_2006.pdf

[18] Trivedi, N.D., Trivedi, U.N., Patel, M.M., Patel, J.K. and Bhandari, A. (2011) Preparation and Evaluation of Floating Matrix Tablet of Ranitidine. American Journal of Drug Discovery and Development, 1, 8-23. https://doi.org/10.3923/ajdd.2011.8.23

[19] Siepmann, J. and Siepmann, F. (2012) Modelling of Diffusion Controlled Drug Delivery. Journal of Controlled Release, 161, 351-362. https://doi.org/10.1016/j.jconrel.2011.10.006

[20] Markl, D. and Zeitler, J.A. (2017) A Review of Disintegration Mechanisms and Measurement Techniques. Pharmaceutical Research, 34, 890-917. https://doi.org/10.1007/s11095-017-2129-Z

[21] Al-Saidan, S.M., Krishnaiah, Y.S.R., Patro, S. and Satyanaryana, V. (2005) In Vitro and in Vivo Evaluation of Guar Gum Matrix Tablets for Oral Controlled Release of Water-Soluble Diltiazem Hydrochloride. AAPS PharmSciTech, 6, E14-E21. https://doi.org/10.1208/pt060105

[22] Enayatifard, R., Saeedi, M., Akbari, J. and Haeri Tabatabaee, Y. (2009) Effect of Hydroxypropyl Methylcellulose and Ethyl Cellulose Content on Release Profile and Kinetics of Diltiazem $\mathrm{HCl}$ from Matrices. Tropical Journal of Pharmaceutical Research, 8, 425-432. https://doi.org/10.4314/tjpr.v8i5.48086

[23] Nizar, M., Hatim, S.A. and Wasfy, M.O. (2011) Evaluation of Hydrophilic Matrix Tablets Based on Carbopol $\left({ }^{\circledR}\right)$ 971P and Low-Viscosity Sodium Alginate for PHIndependent Controlled Drug Release. Drug Development and Industrial Pharmacy, 37, 798-808. 